\title{
Molecular diversity and specificity of acoel worms associated with corals in the Gulf of Eilat (Red Sea)
}

\author{
O. Barneah ${ }^{1,3}$, E. Ben-Dov ${ }^{1,4}$, Y. Benayahu ${ }^{3}$, I. Brickner ${ }^{3}$, A. Kushmaro ${ }^{1,2 *}$ \\ ${ }^{1}$ Avram and Stella Goldstein-Goren Department of Biotechnology Engineering and ${ }^{2}$ National Institute for Biotechnology \\ in the Negev, Ben-Gurion University of the Negev, PO Box 653, Be'er-Sheva 84105, Israel \\ ${ }^{3}$ Department of Zoology, George S. Wise Faculty of Life Sciences, Tel Aviv University, Ramat Aviv, Tel Aviv 69978, Israel \\ ${ }^{4}$ Achva Academic College, MP Shikmim 79800, Israel
}

\begin{abstract}
Epizoic acoel worms are known to inhabit several stony coral genera and one soft coral genus in Eilat (Red Sea). Such acoels were recently found to belong to the genus Waminoa and a new species was described: $W$. brickneri. Worms isolated from several coral species exhibited variability in size and reproductive state, suggesting the presence of more than one species of Waminoa. In the present study we examined the 18S rRNA gene sequences of worms from 6 genera of stony corals from the Gulf of Eilat to reveal the genetic variability of the worms and to study the specificity between these worms and the corals on which they live. The sequences obtained were found to be genetically similar, and they formed a distinct cluster with the 18S rRNA gene sequence of $W$. brickneri. Our results demonstrate that corals belonging to 6 different genera harbored genetically similar worms and thus suggest the existence of low specificity between worms and their coral hosts.
\end{abstract}

KEY WORDS: Acoela $\cdot$ Waminoa $\cdot$ Epizoic worms $\cdot$ Specificity $\cdot$ Coral reef $\cdot$ Eilat Resale or republication not permitted without written consent of the publisher

\section{INTRODUCTION}

The Acoela comprise an extremely diverse taxon of small ( $\sim 0.5$ to $10 \mathrm{~mm}$ long), cryptic, almost exclusively marine worms (Hooge \& Tyler 2005). They are a morphologically varied group of soft-bodied worms (Hooge et al. 2002) lacking a gut cavity and protonephridia (Tyler 2003). Acoels have been reported to inhabit both pelagic and littoral environments (McCoy \& Balzer 2002) and are known to include species that are epibenthic, epiphytic (Hooge \& Tyler 2006) and epizoic on live coral colonies (Trench \& Winsor 1987, Winsor 1990, Barneah et al. 2007a).

Acoel worm phylogeny and their relation to other bilaterians have been extensively studied in the last decade (Ruiz-Trillo et al. 1999, Baguñá \& Riutort 2004, Ruiz-Trillo et al. 2004, Philippe et al. 2011). The phylogenetic work on this group is currently being carried out on 2 levels: phylum and family/genus.
Traditionally classified as an order of the Platyhelminthes (Ruiz-Trillo et al. 1999), acoels were later placed in a new phylum (together with Nemertodermatida) called Acoelomorpha (Baguñá \& Riutort 2004), which was suggested to represent the most basal bilaterian-triploblastic taxon. The findings of a recent phylogenetic study by Philippe et al. (2011) suggest that Acoelomorpha is a sister group of Xenoturbellida (a group of marine worms related to the Deutorostomes), and together they constitute an early branch of Bilateria named Xenacoelomorpha, which is, in turn, the sister group of the Ambulacraria (hemichordates and echinoderms).

Researchers have devoted intensive efforts to obtain finer resolutions of the systematics of the acoel species in several families (Hooge et al. 2002, Hooge \& Tyler 2005). One such work is that by Hooge \& Tyler (2005), who re-organized and revised the largest acoel family, the Convolutidae, which con- 
tains one-third of the Acoela species including the genus Waminoa, the focus of the present study. In a phylogenetic investigation of the Acoela using the nuclear 18S rRNA gene, Hooge et al. (2002) produced a gene tree that revealed a polyphyletic Convolutidae, with larger, endosymbiont-containing acoels grouped separately from small-bodied species. The latter were eventually moved to a new family, the Isodiametridae.

Waminoa brickneri (Ogunlana et al. 2005) is a newly discovered species from the reefs of Eilat (Red Sea) and the second described species in this genus. Worms belonging to this genus are epizoic on living corals in the Gulf of Eilat, where they were detected on 13 species of stony corals and on one soft coral species at depths ranging from 2 to $50 \mathrm{~m}$ and exhibiting wide variability in size and reproductive state (Barneah et al. 2007a).

The presence of Waminoa worms on live coral colonies prompted several hypotheses about the nature of this coral worm association, one of which was that the worms feed on the coral's mucus (Barneah et al. 2007a). This assumption was recently corroborated by the study performed by Naumann et al. (2010). The authors developed a novel labeling technique using stable isotope tracers $\left({ }^{13} \mathrm{C}\right.$ and $\left.{ }^{15} \mathrm{~N}\right)$ that enabled the traceability of ${ }^{15} \mathrm{~N}$-labeled mucus. Results from their study clearly indicated that ${ }^{15} \mathrm{~N}$-labeled mucus compounds were transferred into Waminoa worms, while the continuous increase of $\delta^{15} \mathrm{~N}$ by incorporation of mucus- $\mathrm{N}$ within the worms provided the first evidence for the utilization of coral mucus as a food source by Waminoa.

Waminoa worms possess 2 distinct types of dinoflagellate algal symbionts within their cells: small symbionts 5 to $10 \mu \mathrm{m}$ in diameter, identified as belonging to the genus Symbiodinium (Barneah et al. 2007a) and larger Amphidinium symbionts 12 to $20 \mu \mathrm{m}$ in diameter (O. Barneah unpubl. data). The initial hypothesis that the worms retrieve their algal symbionts from their coral hosts during feeding was examined using denaturing gradient gel electrophoresis (DGGE) profiles of the ITS2 region of Symbiodinium derived from coral hosts and their resident worms. The results revealed that corals and worms possess different phylotypes of Symbiodinium and that worms from different coral hosts can harbor nonidentical strains of Symbiodinium algae (Barneah et al. 2007a). The variation in size and reproductive state together with the possession of variable strains of Symbiodonium by different worms and our previous finding regarding the maternal transmission of algal symbionts (Barneah et al. 2007b) led us to hypothesize that there is more than one species of Waminoa associated with corals in the Gulf of Eilat.

To date, worms belonging to the genus Waminoa and similar epizoic worms are virtually unstudied in terms of genetic diversity. The aim of the present study was to examine the genetic diversity of acoel worms epizoic on different genera of corals in the Gulf of Eilat using 18S rRNA gene sequences.

\section{MATERIALS AND METHODS}

\section{Field observations and collection of worms}

Fieldwork was performed by SCUBA diving on the reef across from the Inter-University Institute for Marine Sciences. Worms were removed from the corals by means of mild streams of water blown over the coral surface using a plastic pipette. The worms were sucked into the pipette and transferred underwater to sealed $50 \mathrm{ml}$ plastic flasks. In the event that a single worm was collected, the worm was transferred underwater into an Eppendorf tube. In the laboratory, water was removed from the flasks (with the worms still attached to the plastic surface) and the worm-containing flasks were immediately frozen $\left(-20^{\circ} \mathrm{C}\right)$.

\section{DNA extraction}

In the first phase of this research several worms (10 to 15) from each coral host were pooled together into a single DNA extraction. In a later stage, DNA was successfully extracted from single worms. Frozen samples were thawed and centrifuged for $1 \mathrm{~min}$ at maximal speed to pellet the worms. Excess water was removed. Genomic DNA was extracted using the PowerSoil purification kit (Mo Bio Laboratories) according to the manufacturer's instructions.

\section{PCR amplification}

Total DNA was used for the amplification of a $\sim 1.4 \mathrm{~kb}$ fragment encompassing part of the 18S rRNA gene using universal 18S rRNA gene primers for eukaryotes: forward NSF370/18, AGGGYTCGA YYC CGGAGA and reversed NSR1787/18, CYG CAG GTT CAC CTA CRG with a Biometra TGradient thermocycler. Reaction mixtures included a $12.5 \mathrm{ml}$ ReddyMix (PCR Master mix containing $1.5 \mathrm{mM}$ $\mathrm{MgCl}_{2}$ and a $0.2 \mathrm{mM}$ concentration of each deoxynu- 
cleoside triphosphate; ABgene), 1 pmol each of the forward and reverse primers, 1 to $2 \mathrm{ml}$ of the sample preparation, plus water to bring the total volume to $25 \mathrm{ml}$. An initial denaturation-hot start of $4 \mathrm{~min}$ at $95^{\circ} \mathrm{C}$ was followed by 30 cycles of the following incubation pattern: $94^{\circ} \mathrm{C}$ for $30 \mathrm{~s}, 54^{\circ} \mathrm{C}$ for $30 \mathrm{~s}$, and $72^{\circ} \mathrm{C}$ for $80 \mathrm{~s}$. The procedure was completed with a final elongation step at $72^{\circ} \mathrm{C}$ for $20 \mathrm{~min}$.

\section{Clone library construction and sequencing}

PCR products were purified by electrophoresis through $1 \%$ agarose gel, stained with ethidium bromide and visualized using a UV transilluminator. The $1400 \mathrm{bp}$ bands were excised from the gel, and the DNA was purified from the gel slices using the Wizard PCR Prep kit (Promega). The gel-purified PCR products were cloned into the pCRII-TOPO-TA cloning vector as specified by Invitrogen and transformed into calcium chloride-competent HD5 $\alpha$ Escherichia coli cells according to the manufacturer's instructions. Plasmid DNA was isolated from individual clones by the Wizard Plus SV Minipreps DNA purification system (Promega). Sequencing with NSF370/ 18 primer was performed by the ABI PRISM dye terminator cycle sequencing ready reaction kit with AmpliTaq DNA polymerase FS and the DNA sequencer ABI model 373A system (Perkin-Elmer). Each sequence was given a name containing the sample name (e.g. Acoela2), the abbreviated name of the coral genera from which worms were removed $(\mathrm{Fav}=$ Favia, Favts = Favites, Acan $=$ Acanthastrea, Echi $=$ Echinophyllia, Sid = Siderastrea, Ples = Plesiastrea , and a library number. The sequences obtained from single worms were given a different designation: the number of the library given first, the word 'single' in parentheses followed by the abbreviation of the coral genus.

\section{Sequence analysis}

MEGA (Molecular Evolutionary Genetics Analysis) version 3.1 (Kumar et al. 2004) was used to de-replicate the libraries of $18 \mathrm{~S}$ rRNA gene sequences for subsequent analyses, by comparing all the sequences in a data set to each other and grouping similar sequences together by $\geq 97 \%$ similarity. The first sequence from each group was chosen as a representative to be used in the phylogenetic analysis. All 18S rRNA gene se- quences of each group were first compared with those in the GenBank database with the Basic Local Alignment Search Tool (BLAST, http://ncbi.nlm.nih. gov/Blast.cgi). Sequences that were identified as non-acoel were discarded (e.g. algae or coral). Chimeric sequences were identified and removed using Bellerophon (Huber et al. 2004). The representative sequences from each of the libraries were aligned using ClustalW with the MEGA package (Kumar et al. 2004) and positions not sequenced in all isolates or with alignment uncertainties were removed. Sequences that were used for the construction of phylogenetic trees were $~ 500 \mathrm{bp}$ long. Phylogenetic trees were constructed using the neighborjoining method (Saitou \& Nei 1987) in the MEGA package (Kumar et al. 2004). Bootstrap re-sampling analysis (Felsenstein 1985) for 100 replicates was performed to estimate the confidence of tree topologies.

\section{RESULTS AND DISCUSSION}

Acoel worms were collected from 14 different stony coral colonies belonging to 6 genera, and $1418 \mathrm{~S}$ rRNA gene libraries were subsequently constructed (Table 1) using universal 18S rRNA primers, yielding 75 sequences (accession numbers: EU884315EU884385, EU980317-EU980324). All the sequences obtained, including those that originated from single worms, showed high similarity (98 to $99 \%$ ) to the $18 \mathrm{~S}$ rRNA gene sequence of Waminoa brickneri (AJ875221) and clustered together in the phylogenetic tree (Fig. 1). It is therefore suggested that this species is the most prevalent in the coral reef of Eilat. The dominance of $W$. brickneri worms on coral

Table 1. Worm samples collected from different coral colonies. See 'Materials and methods' for explanation of library labels

\begin{tabular}{|lcccc|}
\hline $\begin{array}{l}\text { Collection date } \\
\text { (dd.mm.yy) }\end{array}$ & Coral genus & $\begin{array}{c}\text { Depth } \\
(\mathrm{m})\end{array}$ & $\begin{array}{c}\text { Library } \\
\text { label }\end{array}$ & $\begin{array}{c}\text { No. of } \\
\text { sequences }\end{array}$ \\
\hline 11.06 .07 & Acanthastrea & 3 & Acan2 & 9 \\
11.06 .07 & Acanthastrea & 3 & Acan3 & 12 \\
11.06 .07 & Echinophyllia & 2.5 & Echi45 & 14 \\
29.10 .07 & Plesiastrea & 3 & Ples1 & 8 \\
29.10 .07 & Plesiastrea & 3 & Ples5 & 6 \\
29.10 .07 & Faviafavus & 3 & Fav4 & 7 \\
29.10 .07 & Favia favus & 6 & Fav7 & 9 \\
29.10 .07 & Faviafavus & 3 & Fav8 & 8 \\
29.10 .07 & Siderastrea & 8 & Sid9 & 8 \\
15.12 .08 & Echinopora & 9 & A3 (single)-Echi & 2 \\
15.12 .08 & Plesiastrea & 4 & C6 (single)-Ples & 4 \\
15.12 .08 & Favites & 7 & E5 (single)-Favts & 1 \\
16.12 .08 & Siderastrea & 14 & M11 (single)-Sid & 4 \\
16.12 .08 & Siderastrea & 13 & Q8 (single)-Sid & 2 \\
\hline
\end{tabular}


colonies belonging to 6 different genera suggests that we are witnessing low specificity between worms and corals.

The recent findings about the nutrition of Waminoa worms on coral mucus (Naumann et al. 2010) together with previous findings regarding the nonidentical Symbiodinium strains of coral hosts and their worms (hence showing that the worms do not retrieve algae by ingesting coral tissue) suggest that the worms are generalists in terms of their foodchoice and thus are occupying different coral genera. Furthermore, similar worms were observed living on sea anemones (Actinaria) (data not shown), which belong to a different order in the phylum Cnidaria, demonstrating further flexibility in their host choice.

Although acoel worms can occasionally occupy large areas on the tissue of live coral colonies (Barneah et al. 2007a) and can inhabit a variety of coral species, it was not until 2 decades ago that these worms became a focus of biological interest (Trench \& Winsor 1987). Reports regarding acoels containing algal symbionts that are epizoic on corals include several taxa: Haplodiscus sp. from reefs near Micronesia (Trench \& Winsor 1987), Waminoa sp. 1, 2, W. litus, and Convolutriloba hastifera from North Queensland,

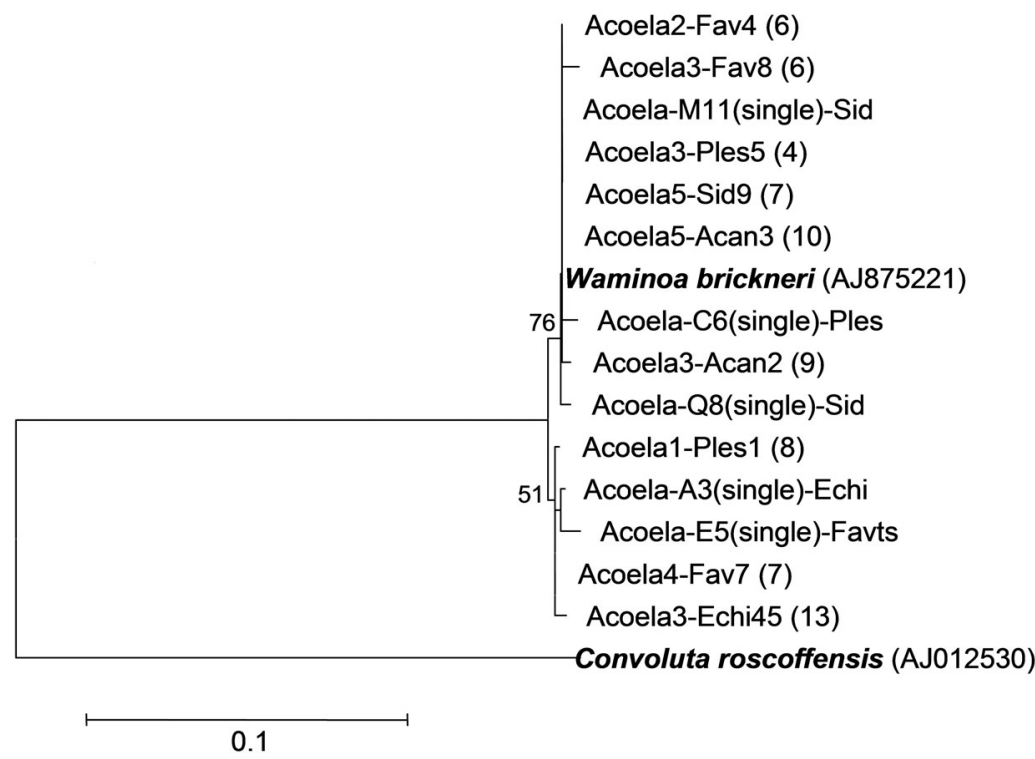

Fig. 1. Phylogenetic tree based on 75 18S rRNA gene sequences of acoel worms that were collected from 14 colonies of stony corals belonging to 6 different genera. Numbers in parentheses: total number of similar clones based on $\geq 97 \%$ identity for each representative sequence. Sequences in bold text represent closely related acoel worms. Main cluster contains sequences 98 to $99 \%$ similar to Waminoa brickneri sequence. The tree was constructed using the neighbor-joining method (Saitou \& Nei 1987) in the MEGA package (Kumar et al. 2004) using partial sequences of 18S rRNA gene (540 bp). Bar: 10 substitutions per 100 nucleotide positions. Bootstrap probabilities (Felsenstein 1985) indicated at branch nodes. See Table 1 for abbreviations
Australia (Winsor 1990). Haplodiscus sp. contains 2 distinct algal symbionts within the same host cell. This worm was described as pelagic, but spends part of its life cycle on the stony coral Porites (Trench \& Winsor 1987). It is possible that pelagic individuals were identified as species of Haplodiscus and the benthic ones as Waminoa (Ogunlana et al. 2005). Thus, although it is likely that species of Haplodiscus sp. may be synonymous with species of Waminoa, verification of this assumption awaits the finding of more live material from both genera (Ogunlana et al. 2005).

The above-mentioned examples are mostly anecdotal and in most cases there are no accompanying molecular data available. The advent of molecular techniques and the use of 18S rRNA sequence data have been shown to be effective in determining the phylogenetic relationships of acoels (Hooge et al. 2002). In the present study we demonstrated that the acoel worms inhabiting corals in Eilat's coral reef are genetically similar and most probably belong to the same species. However, in light of previous phylogenetic studies based on the 18S rRNA sequence data such as the endosymbiotic algae belonging to the genus Symbiodinium and harbored by corals (Rowan \& Powers 1991, LaJeunesse 2001), we are aware of the limitations of this tool. Therefore, in the future it may be necessary to use specific primers or a different gene to increase the resolution of the results.

The present study focused on acoel worms from Eilat's coral reef, which is the northern boundary of coral reef distribution worldwide. Reports of similar worms are accumulating from various locations around the Indo Pacific (Haapkylä et al. 2009) and West Pacific (P. Scaps pers. comm.). The results of the present study strengthen the need for a thorough genetic survey of Waminoa and similar epizoic worms along a wider geographic range. Only this way will we be able to resolve the diversity of species, phylogenetic relations, and evolution of these fascinating worms.

Acknowledgements. This work was supported by ISF Grants 511/02-1 and 1169/ 07 and a VATAT post-doc scholarship to O.B. We are grateful to G. Gefen, U. Sheyn, E. Hadad, M. Bahagan and A. Lazarus for their valuable assistance in the field and in the laboratory. We thank E. KramarskyWinter for helpful comments on the manu- 
script, N. Paz for editorial assistance and the Inter-University Institute in Eilat and the Israel Maritime College in Michmoret for the use of their facilities.

\section{LITERATURE CITED}

Baguñá J, Riutort M (2004) Molecular phylogeny of the Platyhelminthes. Can J Zool 82:168-193

Barneah O, Brickner I, Hooge M, Weis VM, LaJeunesse TC, Benayahu Y (2007a) Three party symbiosis: acoelomorph worms, corals and unicellular algal symbionts in Eilat (Red Sea). Mar Biol 151:1215-1223

- Barneah O, Brickner I, Hooge M, Weis VM, Benayahu Y (2007b) First evidence of maternal transmission of algal endosymbionts at an oocyte stage in a triploblastic host, with observations on reproduction in Waminoa brickneri (Acoelomorpha). Invertebr Biol 126:113-119

> Felsenstein J (1985) Confidence limits on phylogenies: an approach using the bootstrap. Evolution 39:783-791

> Haapkylä J, Seymour AS, Barneah O, Brickner I, Hennige S, Suggett D, Smith D (2009) Association of Waminoa sp. (Acoela) with corals in the Wakatobi Marine Park, SouthEast Sulawesi, Indonesia. Mar Biol 156:1021-1027

Hooge MD, Tyler S (2005) New tools for resolving phylogenies: a systematic revision of the Convolutidae (Acoelomorpha, Acoela). J Zoo Syst Evol Res 43:100-113

Hooge MD, Tyler S (2006) Concordance of molecular and morphological data: the example of the Acoela. Integr Comp Biol 46:118-124

Hooge MD, Haye P, Tyler S, Litvaitis MK, Kornfield I (2002) Molecular systematics of the Acoela (Platyhelminthes) and its concordance with morphology. Mol Phylogenet Evol 24:333-342

Huber T, Faulkner G, Hugenholtz P (2004) Bellerophon: a program to detect chimeric sequences in multiple sequence alignments. Bioinformatics 20:2317-2319

Kumar S, Tomura K, Nei M (2004) MEGA3: integrated software for molecular evolutionary genetics analysis and sequence alignment. Brief Bioinform 5:150-163

Editorial responsibility: Hans Heinrich Janssen, Oldendorf/Luhe, Germany
LaJeunesse TC (2001) Investigating the biodiversity, ecology, and phylogeny of endosymbiotic dinoflagellates in the genus Symbiodinium using the ITS region: in search of a 'species' level marker. J Phycol 37:866-880

McCoy AM, Balzer I (2002) Algal symbiosis in flatworms. In: Seckbach J (ed) Symbiosis: mechanisms and model systems. Kluwer Academic Publishers, Dordrecht, p 561-574

Naumann MS, Mayr C, Struck U, Wild C (2010) Coral mucus stable isotope composition and labeling: experimental evidence for mucus uptake by epizoic acoelomorph worms. Mar Biol 157:2521-2531

Ogunlana MV, Hooge MD, Benayahu Y, Yonas YI, Barneah O, Tyler S (2005) Waminoa brickneri n. sp. (Acoela: Acoelomorpha) associated with corals in the Red Sea. Zootaxa 1008:1-11

> Philippe H, Brinkmann H, Copley RR, Moroz LL and others (2011) Acoelomorph flatworms are deuterostomes related to Xenoturbella. Nature 470:255-258

Rowan R, Powers DA (1991) A molecular genetic classification of zooxanthellae and the evolution of animal-algal symbioses. Science 251:1348-1351

Ruiz-Trillo I, Riutort M, Littlewood DT, Herniou EA, Baguna J (1999) Acoel flatworms: earliest extant bilaterian Metazoans, not members of Platyhelminthes. Science 283: 1919-1923

> Ruiz-Trillo I, Riutort M, Fourcade HM, Baguñá J, Boore JL (2004) Mitochondrial genome data support the basal position of Acoelomorpha and the polyphyly of the Platyhelminthes. Mol Phylogenet Evol 33:321-332

Saitou N, Nei M (1987) The neighbor-joining method: a new method for constructing phylogenetic trees. Mol Biol Evol 4:406-425

Trench RK, Winsor H (1987) Symbiosis with dinoflagellates in two pelagic flatworms, Amphiscolops sp. and Haplodiscus sp. Symbiosis 3:1-22

Tyler S (2003) Platyhelminthes. The nature of a controversial phylum. Available at: http://devbio.umesci.maine.edu/ styler/globalworming/platyhelm.htm

Winsor L (1990) Marine Turbellaria (Acoela) from north Queensland. Mem Queensl Mus 28(2):785-800

Submitted: September 29, 2008; Accepted: December 7, 2011 Proofs received from author(s): January 19, 2012 